\title{
LES VACCINS anti-SARS-Cov-2 et LES QUESTIONS QU'ILS EVOQUENT
}

\author{
Abdel H. Labidi, MD., PhD.
}

\section{Introduction}

Depuis qu'il a été signalé pour la première fois à la fin de 2019, SARS-Cov-2 a eu un impact mondial sur la santé physique et mentale des humains, ainsi que sur leur vie sociale et leur entreprise économique. En un an, le virus a infecté plus de 115 millions de personnes, en a tué près de 2,6 millions et en a laissé beaucoup d'autres avec des séquelles de santé à long terme.

La pandémie de SARS-Cov-2 a submergé les systèmes de santé, a interrompu de nombreux soins de routine et a altéré le suivi des patients. Tous ces facteurs ont conduit à une mortalité accrue due à d'autres maladies chroniques. 
En outre, la pandémie de SARS-Cov-2 a provoqué une perturbation sans précédent de l'éducation, des activités économiques, des voyages et de la vie sociale et a profondément changé notre mode de vie.

Dans cet article de synthèse, nous présentons l'organisation et la fonction du système immunitaire qui nous protège contre les maladies, la virologie, l'infection, la transmission et la pathogenèse du virus SARS-Cov-2, la maladie Covid-19, le développement de vaccins anti-SARS-Cov-2 et certaines des questions soulevées par ces vaccins, ainsi que des suggestions de réponses.

\section{2- LE SYSTÈME IMMUNITAIRE}

La dégradation de tous les systèmes par le vieillissement, l'érosion et les maladies est due à des causes internes à ces systèmes ou venant de leur environnement. Au cours de leur évolution, les organismes vivants ont résisté à cette dégradation en développant des mécanismes de défense pour se protéger (1 - 4).

Les humains ont développé un système immunitaire composé de cellules hautement spécialisées (cellules $B$, cellules T et CPAs telles que macrophages, cellules dendritiques, etc.) qui interagissent avec les molécules du 
Complexe Majeur d'Histocompatibilité (CMH-l et $\mathrm{CMH}-\mathrm{II})$ pour produire une réponse immunitaire humorale et / ou cellulaire. Ces deux réponses interdépendantes du système immunitaire utilisent des cellules spécifiques et ont des rôles complémentaires mais différents.

Le Système Majeur d'histocompatibilité (SMH) : Le SMH joue un rôle essentiel dans la réponse immunitaire. II est composé de deux classes de molécules ( $\mathrm{CMH}-\mathrm{I}$ et $\mathrm{CMH}-\mathrm{II})$

Les molécules du $\mathrm{CMH}-I$ résident autour des organelles, par lesquelles transitent les protéines synthétisées dans la cellule, tel que le réticulum endoplasmique rugueux (RER). Ainsi, leur localisation dans la cellule leur confère leur fonction spécifique de surveiller la synthèse des protéines et de se lier aux antigènes qui sont produits dans l'environnement intracellulaire comme dans le cas de néoplasmes malins ou d'infections intracellulaires. Les lymphocytes-T-CD8 $8^{+}$cytotoxiques reconnaissent et interagissent avec les antigènes présentés en association avec les molécules du $C M H$-I à la surface des cellules présentatrices d'antigène (CPAs), puis prolifèrent et détruisent les cellules malades qui présentent les mêmes antigènes. Les molécules du $\mathrm{CMH}$ - 
I sont exprimées sur toutes nos cellules. Ainsi, toute cellule qui présente un fragment d'antigène anormal ou étranger qui n'a pas été reconnu comme soi pendant le développement et l'éducation des cellules T, est détruite par les lymphocytes-T-CD8+ cytotoxiques (1 - 7).

Les molécules du $\mathrm{CMH}$-II résident autour des vésicules lysosomales et endosomales qui phagocytent et dégradent les antigènes extracellulaires. Ainsi, leur emplacement dans la cellule leur confère leur fonction spécifique de contrôle du contenu de ces vésicules. Elles se lient spécifiquement aux antigènes qui ont été dégradés par voie enzymatique dans les lysosomes ou dans les endosomes. Les lymphocytes-T-CD4+ auxiliaires reconnaissent et interagissent avec les antigènes affichés en association avec les molécules du $\mathrm{CMH}-\mathrm{Il}$ à la surface des CPAs, puis prolifèrent et stimulent les plasmocytes $B$ pour produire des anticorps neutralisants contre l'antigène libre en circulation ou affiché à la surface de la cellule hôte, ainsi que les agents pathogènes circulants. Les molécules du $\mathrm{CMH}-/ /$ ne sont exprimées que sur nos cellules immunitaires. Ainsi, l'activité des 
lymphocytes-T-CD4 ${ }^{+}$auxiliaires se concentre sur les cellules qui participent à la réponse immunitaire, sans impacter les autres cellules de l'organisme (1 - 7).

Les cellules immunitaires: Notre système immunitaire utilise des cellules spécialisées (lymphocytes-B, lymphocytes-T et CPAs tels que macrophages, cellules dendritiques etc.) qui expriment à leur surface des récepteurs spécifiques (MHC-I, MHC-II, RCT, CD4 et CD8). Les cellules T maturent suivant un processus progressif et de sélection à plusieurs étapes pour éviter d'attaquer les cellules de l'organisme.

Les cellules-B ou lymphocytes-B sont ainsi appelés parce qu'ils se développent dans la moelle osseuse. Les cellules plasmocytes- $B$ sont des cellules-B qui produisent des anticorps qui reconnaissent et se lient spécifiquement aux antigènes étrangers libres en circulation ou qui sont affichés à la surface des cellules pathogènes. Ces anticorps peuvent être monoclonaux (se lient spécifiquement à un seul épitope sur l'antigène) ou polyclonaux (se lient à plusieurs épitopes sur l'antigène). 
Les cellules-T ou lymphocytes-T sont ainsi appelés parce qu'ils se développent dans le thymus. Ils ne produisent pas d'anticorps mais sont équipés de molécules de type anticorps appelées récepteurs de cellules $T$ (RCT). Contrairement aux anticorps, les RCTs ne reconnaissent que les fragments d'antigène produits dans l'environnement intracellulaire puis exportés et affichés en association avec des molécules $\mathrm{CMH}-\mathrm{I}$ ou $\mathrm{CMH}-\mathrm{Il}$ à la surface de la cellule. Les RCTs sont très spécifiques et précis dans la reconnaissance des antigènes produits dans l'environnement intracellulaire.

Les gènes qui encodent pour les anticorps et les RCTs sont assemblés à partir de petits fragments d'ADN qui proviennent de différentes familles de gènes, dans un processus qui peut générer jusqu'à $10^{14}$ combinaisons. Par conséquent, quelle que soit la rareté d'un antigène, il y aura toujours un anticorps ou un RCT capable de le reconnaître. C'est aussi pourquoi il ne faut pas avoir peur de s'aventurer hors de notre planète car notre système immunitaire a de bonnes chances de relever les défis antigéniques venant de nouvelles frontières spatiales qui, avec les progrès technologiques, ne seront plus hors de notre portée. 
Education des cellules $\mathrm{T}$ : Les réponses immunitaires humorales et cellulaires impliquent les lymphocytes-T, mais la nature et le résultat de la réponse immunitaire dépendent de la sous-classe de lymphocytes- $T$ activée ainsi que des cytokines présentes dans le microenvironnement cellulaire où la maturation et l'activation des lymphocytes-T se déroulent (1 - 4).

Nos cellules-T subissent un processus rigoureux d'éducation en deux étapes dans le thymus pour apprendre à faire la distinction entre les auto-peptides et les non-auto-peptides. Ce processus a été surnommé la sélection positive / négative. II implique les molécules $M H C-I, M H C-I I, R C T, C D 4$ et $C D 8$. Les molécules $C D 4$ et $C D 8$ sont des corécepteurs qui sont réticulés avec les RCTs par les molécules du CMH pendant la maturation et l'activation des précurseurs des cellules- $T$ en cellules-T matures.

Les précurseurs des cellules- $T C D 4^{+}$et des lymphocytes- $T C D 8^{+}$matures sont des thymocytes qui expriment les RCTs et les deux récepteurs $C D 4$ et $C D 8$. Ces thymocytes double-positifs $\left(C D 4^{+}-C D 8^{+}\right)$subissent, dans le thymus, 
un test de complémentarité entre leurs $R C T s$ et les molécules $C M H-I$ ainsi que $C M H$-II qui présentent des autopeptides à la surface des CPAs.

Les thymocytes double-positifs $\left(C D 4^{+}-C D 8^{+}\right)$dont les RCTs ne montrent aucune complémentarité avec les complexes $\mathrm{CMH}$-auto-peptides sont jugés inutiles et meurent par une apoptose génétiquement programmée. C'est ce qu'on appelle « apoptose par négligence ».

Les thymocytes double-positifs $\left(C D 4^{+}-C D 8^{+}\right)$dont les $R C T s$ montrent une forte complémentarité avec les complexes $\mathrm{CMH}$-auto-peptides provoqueraient des maladies auto-immunes s'ils étaient libérés en circulation. Par conséquent, ils sont sélectionnés négativement pour mourir par apoptose induite par l'antigène via la signalisation RCT. Ceci est appelé « suppression clonale ou tolérance centrale ».

Enfin, les thymocytes double-positifs $\left(C D 4^{+}-C D 8^{+}\right)$dont les $R C T s$ ne reconnaissent que les molécules $C M H-l$ et CMH-Il qui ne sont pas associées aux auto-peptides sont sauvés de l'apoptose par négligence et sont sélectionnés positivement pour poursuivre la maturation. 
Les thymocytes double-positifs $\left(C D 4^{+}-C D 8^{+}\right)$dont les récepteurs $R C T$ et $C D 8$ deviennent réticulés au cours de leur interaction avec les molécules du CMH-I se développent en lymphocytes-T CD8 ${ }^{+}$cytotoxiques. Les cellules de cette lignée reconnaissent et détruisent les cellules pathogènes qui apparaissent dans l'organisme.

Les thymocytes double-positifs $\left(C D 4^{+}-C D 8^{+}\right)$dont les récepteurs $R C T$ et $C D 4$ deviennent réticulés au cours de leur interaction avec les molécules du $C M H$-II se développent en lymphocytes- $T$ CD4 ${ }^{+}$auxiliaires ou en lymphocytes Treg immunosuppresseurs. Les cellules de ces lignées aident ou suppriment les activités des lymphocytes- $T$ et des lymphocytes- $B$.

La sélection négative n'est pas un processus parfait. Certains des thymocytes double-positifs $\left(C D 4^{+}-C D 8^{+}\right)$qui reconnaissent les auto-peptides peuvent échapper à l'apoptose par négligence. Mais pour continuer leur développement ils doivent survivre le processus de sélection positive et résister à l'effet immunosuppresseur des cellules-Treg $C D 4^{+}$en circulation. S'ils réussissent à échapper à ce système de contrôle à plusieurs étapes, ils peuvent provoquer des maladies auto-immunes. 
Les voies de maturation des cellules-T CD4+ auxiliaires : Les cellules- $T C D 4^{+}$naïves se développent dans le tissu lymphoïde en cellules-T CD4 ${ }^{+}$auxiliaires par l'une des voies de maturation suivantes : Th-1, Th-2, Th-17 ou Treg (8).

Elles maturent par la voie Th-1 en présence d'IL-12 et d'INF- $y$. Les lymphocytes-T CD4 ${ }^{+}$auxiliaires de cette voie jouent un rôle dans l'immunité cellulaire. La réponse immunitaire Th-1 utilise le facteur de stimulation des colonies de macrophages granulocytes (FSCMG) pour activer la prolifération des cellules phagocytaires (4). Elle stimule les lymphocytes- $T C D 8^{+}$cytotoxiques et les dirige pour identifier et détruire les cellules devenues pathogènes par les infections intracellulaires, les désordres auto-immuns ou les maladies cancéreuses.

Elles maturent par la voie Th-2 en présence d'IL-4 et de TNF- $\alpha$. Les lymphocytes-T CD4+ auxiliaires de cette voie jouent un rôle dans l'immunité humorale. La réponse immunitaire Th-2 inactive la prolifération des cellules phagocytaires (1 - 3). Elle implique des cellules plasmocytes-B qui produisent des anticorps qui reconnaissent et 
neutralisent les antigènes ou agents pathogènes circulants dans le milieu extracellulaire, ainsi que les antigènes affichés sur les cellules pathogènes.

Elles maturent par la voie Th-17 en présence d'IL-76, et une faible concentration du Facteur de Croissance Transformant ( $\beta F C T)$. Les lymphocytes-T $C D 4^{+}$auxiliaires de cette voie jouent un rôle dans les réponses immunitaires inflammatoires. La voie Th-17 est activée dans les réactions immunitaires exacerbées.

Elles maturent par la voie Treg Foxp3 positif en présence d'une concentration élevée de BFTC. Les lymphocytes$T C D 4^{+}$auxiliaires de cette voie jouent un rôle dans les réponses immunitaires immunosuppressives antiinflammatoires. La voie Treg est activée dans les réponses immunitaires inefficaces qui caractérisent de nombreuses infections intracellulaires ainsi que les maladies auto-immunes et cancéreuses.

L'équilibre entre les voies de la réponse immunitaire : L'équilibre entre les réponses immunitaires Th-1 et Th-2 détermine si la réponse immunitaire principale à une maladie est cellulaire ou humorale. 
L'équilibre entre les réponses immunitaires Th-17 et Treg régule l'activité des cellules immunitaires des voies Th-1 et Th-2 et ainsi détermine si la réponse immunitaire à une maladie réussira ou échouera (8).

Cependant, une activation déséquilibrée des voies Th-2 et Th-17 peut surproduire des cytokines qui provoquent une inflammation majeure, une destruction tissulaire et une nécrose. Cette réaction excessive du système immunitaire se produit dans de nombreuses maladies telles que la lèpre lépromateuse où elle cause de graves dommages à l'hôte, ou peut être mortelle comme dans le syndrome de tempête de cytokines et le syndrome thrombogène observés chez les patients gravement atteints par SARS-Cov-2 $(1-3,9)$.

\section{Antigènes, immunogènes et immunité protectrice}

Un antigène est une substance étrangère qui peut ou non déclencher une réponse immunitaire.

Un immunogène est un antigène qui déclenche une réponse immunitaire.

Une immunité protectrice est une réponse immunitaire capable d'éliminer l'immunogène de l'organisme. 
La protéine de spécule (Proteine-S) de SARS-CoV-2 est un immunogène qui stimule le système immunitaire à produire des anticorps neutralisants contre SARS-CoV-2. Pour cette raison, la protéine-S est au centre du développement de vaccins anti-SARS-CoV-2 et elle est la cible du développement rationnel de médicaments qu'on peut utiliser en thérapeutique contre la Covid-19.

\section{3- Le coronavirus 2 du syndrome respiratoire aigu sévère (SARS-Cov-2)}

Les coronavirus sont appelés ainsi en raison de l'apparition d'un halo ou d'une couronne autour de leur enveloppe lorsqu'ils sont observés sous microscope électronique (Corona est le mot latin pour couronne ou halo). Ces virus à $A R N$ ont un taux de mutation beaucoup plus élevé que les virus à $A D N$ car l'ARN polymérase n'a pas la fonction d'édition présente dans l'ADN polymérase. Ainsi, en plus de la vitesse élevée de production de virus, les virus à $A R N$ peuvent muter dans la cellule hôte à un taux beaucoup plus élevé et submerger davantage le système immunitaire grâce à un mécanisme appelé " rapidité et changement de forme " par opposition au mécanisme de «Camouflage et sabotage » associés aux virus à $A D N$ (20). 
SARS-CoV-2 est un coronavirus enveloppé à ARN positif simple brin. Il est composé d'un génome d'ARN associé

à la nucléoprotéine structurale (protéine-N), de protéines accessoires, d'une enveloppe en bicouche phospholipidique et de trois autres protéines structurales ancrées dans l'enveloppe virale. Ces dernières sont la protéine d'enveloppe (protéine-E), la protéine membranaire (protéine-M) et la protéine de spécule (protéine-S). La protéine-S sort de la surface de l'enveloppe du virus et lui donne son aspect spécifique de couronne sous microscopie électronique. La structure de SARS-Cov-2 est illustrée dans la Figure 1 ci-dessous.

SARS-Cov-2 a un génome de 29881 paires de bases (GenBank $n^{\circ}$ MN908947) qui est organisé en un seul ARN positif simple brin. Le génome $A R N$ du SARS-Cov-2 encode dans le cytoplasme de la cellule hôte seize protéines non structurales dites accessoires qui forment un complexe de réplication-traduction (CRT). Le CRT utilise le génome viral à polarité positive comme matrice pour produire un ARN à polarité négative. Ce dernier est ensuite utilisé comme matrice pour produire de l'ARN génomique virale à polarité positive. Le CRT intervient également dans la synthèse de la protéine- $N$ qui forme en association avec l'ARN génomique viral, le complexe 
nucléocapside. Celui-ci est alors intégré avec les protéines accessoires dans des particules virales nouvellement produites. La protéine- $N$ joue également un rôle dans la synthèse de l'ARN.

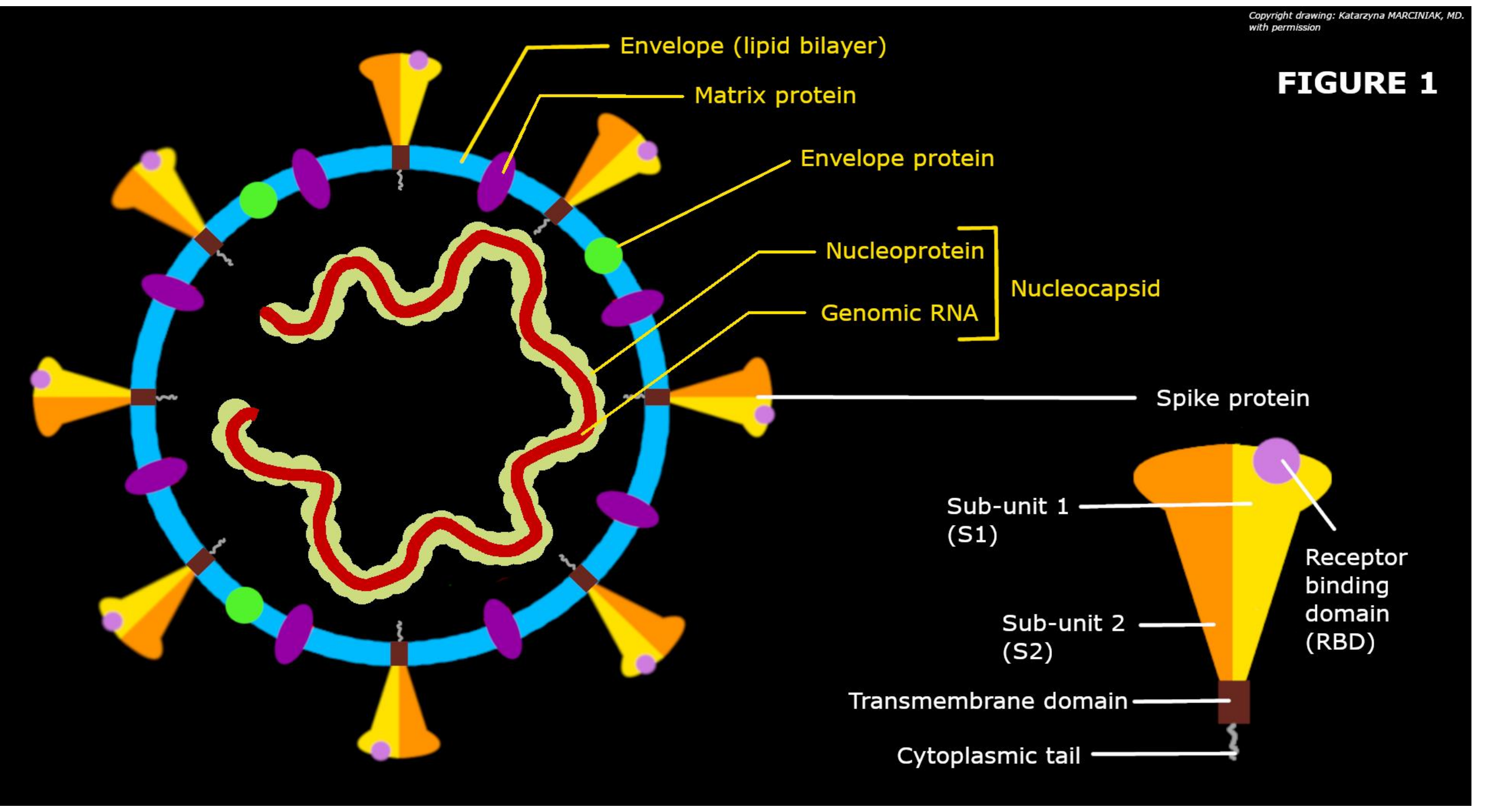


Le génome ARN de SARS-Cov-2 encode en outre dans le réticulum endoplasmique rugueux (RER) pour trois autres protéines structurales $E, M$, et $S$. Après modification dans le complexe RER-Golgi, ces protéines forment en association avec des phospholipides l'enveloppe virale (22). Les protéines $E$ et $M$ sont également nécessaires pour l'assemblage viral. La protéine-S est utilisée pour se fixer et entrer dans la cellule hôte.

La protéine- $N$ contient des domaines terminaux $\mathrm{N}$ et $\mathrm{C}$ (NTD et CTD) qui se lient aux molécules d'ARN. Sa structure contient des domaines sérine-arginine $(S R / R S)$ hautement conservés dans toutes les espèces et elle est enrichie en résidus aminoacides basiques. Ces attributs structuraux permettent à la protéine- $N$ d'envelopper et d'enrouler les molécules d'ARN acide à polarité positive dans le complexe nucléocapside. Ce processus est très efficace et spécifique pour les molécules d'ARN à polarité positive, qui ont la séquence et la taille correctes pour former des particules virales matures. La protéine- $N$ interagit également avec la protéine- $M$ pour faciliter le processus d'empaquetage génomique viral dans les virions nouvellement produits $(23,24)$. 
La protéine-S est une glycoprotéine transmembranaire qui intervient dans l'attachement, la fusion et l'entrée de SARS-Cov-2 dans la cellule hôte via le récepteur de l'Angiotensine Convertase II (ACE-2). Elle est composée de 1273 acides aminés, qui s'assemblent en homotrimère à la surface de l'enveloppe du virus lui donnant la décoration spécifique des Coronavirus. Les 1273 résidus d'acides aminés sont organisés dans le sens du côté $N$ terminal vers le côté $C$-terminal, en plusieurs domaines dont le signal peptidique (SP), la sous-unité (S1) qui contient 685 acides aminés, la sous-unité (S2) qui contient 588 acides aminés, le site de clivage Furin situé à la jonction S1 / S2, le domaine transmembranaire (TM) et la queue cytoplasmique (CT), entre autres.

La sous-unité S1 contient un domaine de liaison au récepteur (RBD) qui utilise son motif (RBM) pour reconnaître et se lier au récepteur ACE-2. La sous-unité S2 facilite la fusion entre l'enveloppe du virus et la membrane cytoplasmique de la cellule hôte (16). L'emplacement de la protéine-S à la surface de l'enveloppe de SARS-Cov2 en a fait une cible principale pour la réponse immunitaire de l'hôte. La réponse immunitaire humorale produit des anticorps qui reconnaissent et réagissent avec des déterminants antigéniques présents sur la protéine-S et 
empêchent l'infection des cellules hôtes par SARS-Cov-2, d'où une protection contre la maladie Covid-19. Une étude qui a suivi 1241 patients séropositifs pendant 127 jours et 11052 patients séronégatifs pendant 188 jours n'a trouvé aucun cas d'infection symptomatique et 3 cas d'infection asymptomatique dans le groupe séropositif mais 89 cas d'infection symptomatique ainsi que 79 cas d'infection asymptomatique chez le groupe séronégatif (10). Une autre étude a montré que les cellules de mémoire immunitaires étaient détectables jusqu'à 8 mois après l'infection par SARS-Cov-2 (11). La conclusion est que les anticorps protègent contre l'infection par SARSCov-2. Ainsi, la protéine-S est au centre du développement de vaccins anti-SARS-Cov-2, et elle est une cible pour la conception rationnelle de médicaments pour produire des thérapies contre Covid-19. L'organisation de la séquence d'acides aminés de la protéine-S est représentée dans la Figure-2 ci-dessous : 


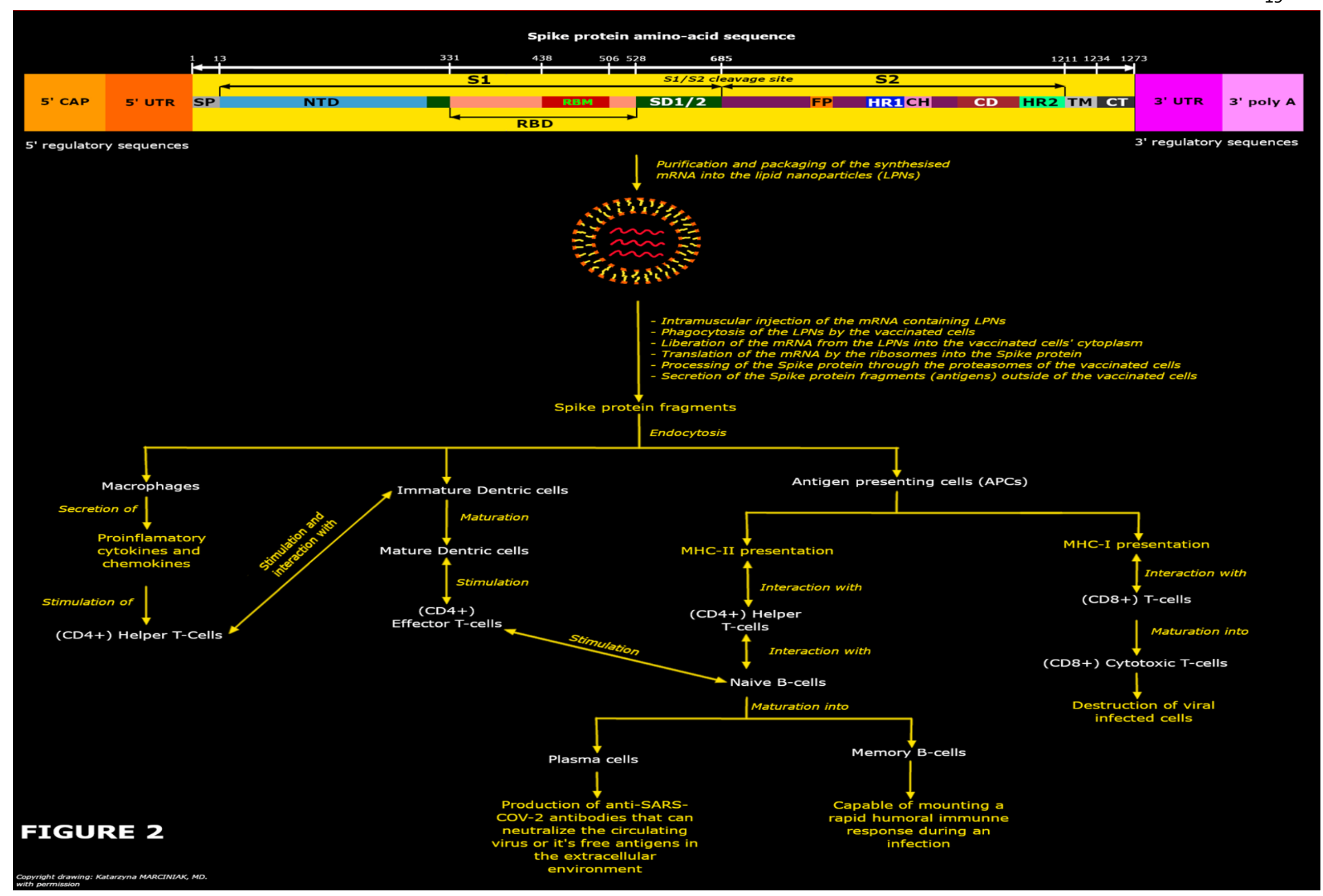


Néanmoins, tous les anticorps produits après l'infection par SRAS-Cov-2 ne sont pas nécessairement protecteurs. Certains anticorps non neutralisants peuvent compliquer la réponse immunitaire en facilitant l'entrée du virus dans d’autres cellules cibles grâce à un mécanisme qui a été appelé « Amélioration dépendante des anticorps » (12). Cela pourrait expliquer pourquoi l'utilisation du plasma de sujets en convalescence comme traitement a donné des résultats mitigés $(61,62)$.

Le mécanisme d'attachement et d'entrée de SRAS-Cov2 dans la cellule hôte nécessite un réarrangement à la fois de la protéine-S et du récepteur ACE-2. SRAS-Cov-2 utilise sa protéine-S pour se fixer au récepteur ACE-2 présent sur la membrane cytoplasmique de la cellule hôte. Ensuite, soit il fusionne son enveloppe avec la membrane cytoplasmique de la cellule hôte, soit il est endocytosé via la voie endosomale et une fois à l'intérieur de la cellule hôte, il fusionne son enveloppe avec la membrane endosomique. L'entrée de SRAS-Cov-2 dans la cellule hôte via la voie endosomale est médiée par un pH acide et des cathepsines endosomales. L'entrée de SRAS-Cov2 par fusion avec la membrane cytoplasmique de la cellule hôte est médiée par des protéases telles que la sérine 
protéase transmembranaire de type-2 (TMPRSS2) ou la trypsine des voies respiratoires humaines (HAT), et l'endopeptidase membranaire Furine qui fait la navette entre le Complexe Trans-Golgi et la surface de la cellule hôte. D'une part la TMPRSS2 clive le récepteur ACE-2, et d'autre part elle amorce le précurseur de la protéine-S pour aider la Furine à agir sur le site de clivage situé à la jonction S1 / S2 et séparer les sous-unités S1 et S2.

Dans les deux cas, SRAS-Cov-2 réussit à libérer son génome d'ARN et ses enzymes essentielles dans le cytoplasme de la cellule hôte.

Dans le cytoplasme de la cellule hôte, le génome viral subit un décapsulage de la nucléocapside pour dissocier la protéine- $N$ de l'ARN. L'ARN génomique libéré est alors prêt à être transcrit et traduit. La première à être produite est une réplicase de SRAS-Cov-2. Celle-ci est produite sous forme d'une poly-protéine dont le clivage par les protéases virales va engendrer 16 protéines accessoires qui forment le $C R T$. Ensuite, une matrice d'ARN à polarité négative est synthétisée. Par la suite SRAS-Cov-2 utilise la machinerie cellulaire pour se reproduire comme décrit ci-dessus. Les enzymes essentielles de SRAS-Cov-2 nouvellement produites, les protéines $S$, $M$ et 
E, et les nucléocapsides sont intégrées dans des virions qui bourgeonnent dans la lumière de l'appareil RER-Golgi pour former des virions matures qui sont libérés de la cellule hôte. Ainsi démarre un nouveau cycle d'infection et de propagation (22).

SRAS Cov-2 a un tropisme à cellules multiples. Comme le récepteur ACE-2 est présent sur les cellules de plusieurs organes, SRAS Cov-2 peut infecter et se multiplier dans tous ces organes. Ce tropisme multicellulaire de SRASCov-2 ainsi que son génome $A R N$ lui donnent l'avantage d'évoluer plus rapidement, de franchir la barrière des espèces et de se propager chez d'autres hôtes, d'infecter plusieurs organes vitaux de l'organisme et de s'exprimer sous multiples formes cliniques.

\section{4- Covid-19, la maladie causée par SRAS-Cov-2}

Comme pour d'autres agents pathogènes, l'évolution clinique de l'infection par SRAS-Cov-2 va dépendre de l'inoculum et de la virulence du variant viral circulant dans la population. Généralement, les phases suivantes sont distinguées : 
La phase d'incubation : Après avoir contracté SRAS-Cov-2, la phase d'incubation dure environ 5 jours. Au cours de cette phase, le virus continue à se multiplier dans le corps à grande vitesse, mais la personne infectée n'a pas encore développé de symptômes. La quantité de virus accumulée dans l'organisme atteint un maximum entre le $7^{\text {eme }}$ et le $10^{\text {eme }}$ jour après l'infection puis commence à baisser au cours des jours suivants sous la pression du système immunitaire.

La phase clinique: Les symptômes commencent vers le $6^{\text {ème }}$ jour après l'infection et continueront à se développer même si la quantité de virus dans le corps commence à baisser sous la pression du système immunitaire. Cette phase peut prendre plusieurs formes:

Dans les formes silencieuses ou non-sévères, le patient ne développe pas de symptômes et n'a aucune idée qu'il a contracté SRAS-Cov-2. II ne découvre ce fait que lorsque son médecin traitant demandera une recherche des anticorps anti-SRAS-Cov-2 lors d'un examen sanguin de routine qui a lieu plusieurs semaines après l'exposition. 


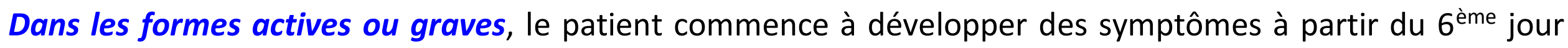
après l'infection. L'intensité de ces symptômes varie d'une personne à l'autre. Certains patients développent une forme modérée de la maladie qui culmine entre le $10^{\mathrm{eme}}$ et le $14^{\mathrm{eme}}$ jour, puis revient à la normale le $15^{\mathrm{eme}}$ jour après l'infection. D'autres patients verront leurs symptômes s'aggraver avec une hyper-inflammation (Syndrome de tempête de cytokines) nécessitant une hospitalisation et même une admission dans l'unité des soins intensifs (USI). Certains de ces cas critiques vont malheureusement être fatal. En fait, la réponse immunitaire du corps humain à l'infection par SRAS-Cov-2 est une arme à double tranchant. En essayant de nous protéger, notre système immunitaire participe également aux complications sévères de la maladie (9).

Les patients à haut risque de morbidité et de mortalité comprennent les personnes âgées et celles souffrant de maladies chroniques [pulmonaire, hépatique, rénale (insuffisance, dialyse, MRC), hypertension artérielle, cardiovasculaire (thrombotique, myocardite, arythmie, insuffisance cardiaque, syndromes coronaires), 
neurologique (démence), endocrinienne (diabète sucré de type 1 et 2), néoplasme malin non hématologique, néoplasme hématologique, immunodéficience, greffes, syndrome de Down, etc.].

\section{5- VACCINATION}

La première vaccination chez l'homme aurait été une immunité maternelle passive dans laquelle la première femme enceinte a pu immuniser son fœtus par transport transplacentaire d'anticorps protecteurs pendant sa grossesse.

La vaccination active repose sur les deux réponses du système immunitaire. L'immunité humorale qui utilise des anticorps pour neutraliser le virus circulant dans le milieu extracellulaire et l'immunité cellulaire qui utilise des lymphocytes-T cytotoxiques pour détruire les cellules infectées résistantes aux anticorps.

De nombreuses plates-formes technologiques ont été développées pour concevoir et préparer des vaccins contre diverses maladies. Plusieurs de ces technologies sont aujourd'hui mises en œuvre pour développer des vaccins anti-SRAS-COV-2. Les principaux types sont répertoriés dans le Tableau-1 ci-dessous : 


\begin{tabular}{|c|c|c|c|c|c|}
\hline Table-1 & & & & & \\
\hline Institution & Vaccine Type & Antigen targeted & Doses & Storage & Efficicacy \\
\hline Pfizer-BioNTech & mRNA & Spike Protein & 2 & $-70^{\circ} \mathrm{C}$ & $95 \%$ \\
\hline Moderna & mRNA & Spike Protein & 2 & $-20^{\circ} \mathrm{C}$ & $95 \%$ \\
\hline Novavax & Subunit & S \& M proteins & 2 & $+4^{\circ} \mathrm{C}$ & $90 \%$ \\
\hline Sinopharm & Inactivated Whole Virus & Whole virus & 2 & $+4^{\circ} \mathrm{C}$ & $79 \%$ \\
\hline Johnson and Johnson & Non-Replicating Vector & Spike Protein & 1 & $+4^{\circ} \mathrm{C}$ & $72 \%$ \\
\hline Astra Zenica & Replicating vector & Spike Protein & 2 & $+4^{\circ} \mathrm{C}$ & $62 \%-90 \%$ \\
\hline Gamaleya National center & Replicating Vector & Spike Protein & 2 & $+4^{\circ} \mathrm{C}$ & $92 \%$ \\
\hline
\end{tabular}

1) Vaccins à base de virus entiers, inactivés ou atténués par divers mécanismes

2) Vaccins à base de sous-unités de protéines pathogènes ou à base de particules virales (VLP)

3) Des vaccins basés sur des vecteurs viraux réplicatifs ou non réplicatifs. Cette technologie remonte aux années 1980. Elle utilise des virus à $A D N$ non pathogènes pour infecter les cellules hôtes. Le vecteur viral est génétiquement modifié pour transporter, délivrer et exprimer à l'intérieur des cellules hôtes, les gènes qui 
encodent pour des immunogènes qui suscitent une immunité protectrice chez l'hôte. Cependant, les vaccins vivants sont risqués chez les personnes immunodéprimées.

4) Vaccins à base d'ADN. Cette technologie remonte aux années 1990. Ces vaccins nécessitent la technique d'électroporation pour faciliter l'entrée de l'ADN dans les cellules hôtes et augmenter son immunogénicité

5) Vaccins à base d'ARNm non réplicatif et non auto-amplifié. Les molécules d'ARNm sont encapsulées dans des nanoparticules lipidiques appelées micelles amphipathiques ou LPNs pour leur stabilité et pour faciliter leur passage à travers la membrane cellulaire. Ce type de vaccin n'est pas stable à température ambiante, d'où la nécessité de le conserver sous forme congelée à très basse température. Une fois à l'intérieur de la cellule hôte, les micelles libèrent leur contenu d'ARNm dans le cytoplasme où il est traduit en protéines qui sont métabolisées et exportées à la surface des $A P C s$ pour susciter une réponse du système immunitaire (Fig-2). L'ARNm traduit est dégradé dans le cytoplasme de la cellule hôte. II n'entre pas dans le noyau et il ne s'intègre pas dans le matériel génétique de cellule-ci. 
En résumé, l'ARNm constitue un vecteur génétique minimal non infectieux, non immunogène en lui-même, non intégratif, rapidement synthétisé au laboratoire, conditionné et efficacement délivré, stable et traduit par les ribosomes dans le cytoplasme de la cellule hôte puis il est dégradé après la traduction.

Vaccins anti-SRAS-Cov-2 : Un an après l'épidémie, des centaines de projets de vaccination sont en cours de développement, dont quelques-uns sont déjà approuvés et utilisés dans les campagnes de vaccination, et plusieurs autres sont en cours d'essais cliniques (Tableau-1).

Dans cet article, nous ne discutons que les vaccins à $A R N m$ qui encodent pour la protéine-S de SRAS-Cov-2. L'ARNm est produit in vitro à partir d'une matrice d'ADN. La matrice contient le cadre de lecture de la protéine$S$ flanqué à son extrémité 3-prime par une région non traduite (UTR) et une queue polyA, et à son extrémité 5prime par une structure Cap1 et une UTR pour conférer la stabilité, stimuler la biogenèse et augmenter l'efficacité de la traduction de l'ARNm. L'ARNm purifié est encapsulé dans des LPNs pour améliorer son absorption par les cellules vaccinées (17 - 19, 21, Fig-2). 


\section{6- QUESTIONS \& RÉPONSES}

\section{Pourquoi devrions-nous développer des vaccins contre le SRAS-Cov-2?}

Les vaccins en général sont considérés comme la couronne de la médecine. Contrairement aux médicaments thérapeutiques, leur utilisation est moins fréquente, leur protection contre la maladie est plus longue et leur coût est beaucoup plus faible. Les vaccins sont très importants pour soutenir l'économie en réduisant la gravité des maladies dans la population et en la maintenant en bonne santé et prospère (30). Au cours de la pandémie de SRAS-Cov-2, une augmentation de la mortalité toutes causes confondues a été signalée (31). Nous ne pouvons donc pas attendre jusqu'à ce que l'infection naturelle produise une immunité de la population humaine, car cela s'est avéré ne pas être une option dans certains pays (32). 
L'ADN ou I'ARN étranger délivré dans les cellules de l'hôte vacciné peut-il s'intégrer et modifier son propre matériel génétique?

Un vaccin doit être basé sur des faits et des connaissances scientifiques qui changent et évoluent avec le temps. Pour vaincre l'épidémie, nous devons agir rapidement mais sur des principes solides. De nombreuses incertitudes et questions restent encore sans réponse. La décision doit être prise en fonction des particularités de chaque personne. Pour rappel, les cellules humaines, à l'exception des globules rouges matures, les cellules carnifiées de la peau, des cheveux et des ongles, sont des cellules eucaryotes nucléées. Ils ont leur matériel génétique sous forme d'ADN organisé et structuré en chromosomes. Les chromosomes sont localisés dans un compartiment séparé, le noyau, qui est entouré d'une membrane nucléaire active. La communication de la membrane nucléaire avec le cytoplasme de la cellule vaccinée est fortement régulée par celle-ci.

L'ADN génomique est constitué de régions appelées EXONS qui encodent (s'expriment) pour des protéines, et de régions appelées INTRONS qui sont non encodantes (ou non exprimées, silencieuses ou interférentes). Les 
introns constituent la majorité de l'ADN humain. Les exons sont organisés en gènes et en séquences régulatrices. Ces dernières contrôlent la transcription des séquences encodantes au sein du gène (ORF) en $A R N m$, dans le noyau. L'ARNm quitte alors le noyau pour être traduit en protéines par les ribosomes dans le cytoplasme.

Le processus de synthèse des protéines dans les cellules eucaryotes commence dans le noyau par la transcription des gènes en molécules d'ARNm primaires. Celles-ci sont modifiées par excision des introns et connexion des exons pour produire des molécules d'ARNm matures. Ces dernières quittent le noyau pour être traduites en protéines par les ribosomes dans le cytoplasme.

L'insertion d'un fragment d'ADN dans une autre molécule d'ADN peut ne pas avoir de conséquences ou bien provoquer des changements profonds. Selon la position de l'insertion, elle peut activer un nouvel ORF, ou désactiver un existant. Pour ces raisons, la sécurité des vaccins à $A D N$ injectés directement ou vectorisés soulève des questions légitimes quant à leur sécurité. En principe, les vaccins utilisant du matériel génétique dérivé d'un agent infectieux ne devraient pas présenter de risque pour l'hôte vacciné étant donné le soin apporté à la mise 
au point de ces vaccins. Aussi, il ne faut pas perdre de vue le fait que même les vaccins classiques inactivés ou vivants atténués contiennent la totalité de l'agent infectieux avec ses lipides, glucides, protéines et bien sûr son matériel génétique ( $A D N$ et $A R N)$. En plus, nous avons de nombreuses années d'expérience avec les vaccins à $A R N m$ utilisés dans le traitement des néoplasmes malins et de certaines maladies infectieuses. En outre, l'ARNm est délivré dans le cytoplasme de la cellule hôte où il est traduit par les ribosomes puis il est dégradé après une courte durée de vie. Par conséquent, il ne doit pas entrer en contact avec le noyau de la cellule hôte où se trouvent les chromosomes. Mais l'utilisation de vecteurs viraux à ADN réplicatifs dont les transactions moléculaires enzymatiques sont les mêmes que celles de l'ADN humain soulève des questions sur l'interaction et l'intégration possibles de l'ADN viral dans le matériel génétique des cellules vaccinées, et les conséquences d'un tel événement (63 - 66). 
Nos cellules sont-elles capables de dégrader et de recycler I'ARNm synthétique?

L'incorporation de ribonucléotides dans la synthèse d'ARN se produit uniquement sur le carbone 3-prime de la molécule de ribose dans la nature. Cependant, chimiquement, il est également possible d'utiliser le carbone 2prime. Puisque le vaccin à $A R N m$ est constitué de molécules d'ARNm synthétiques obtenues par transcription à partir d'une matrice d'ADN, nous nous posons les questions suivantes:

1) Le vaccin à $A R N m$ comprend-il uniquement des molécules d'ARNm qui ont été allongées sur le carbone 3prime?

2) Qu'est-ce qui a été fait pour éviter l'élongation sur le carbone 2-prime ou pour se débarrasser de ces molécules d'ARNm si le vaccin produit contient un mélange de molécules d'ARNm C-2 prime et d'ARNm C3 prime?

3) L'ARNm est dégradé après traduction. Les cellules humaines sont-elles capables de dégrader l'ARNm synthétisé par allongement sur le carbone 2-prime? 
4) Le processus de transcription utilisé pour produire le vaccin à $A R N m$ a-t-il été prouvé qu'il ne produisait pas de fragments d'ARNm partiellement synthétisés ?

5) Est-ce que l'élongation sur le carbone C-2 prime produit des molécules d'ARNm partiellement synthétisées ou instables?

6) Le vaccin à $A R N m$ comprend-t-il uniquement une population homogène de molécules complètes d'ARNm ?

7) Le vaccin à $A R N m$ comprend-t-il des molécules incomplètes d'ARNm et si oui, qu'est-ce qui a été fait pour les éliminer ?

8) Les molécules incomplètes d'ARNm sont-elles intégrées dans les $L P N s$ avec les molécules complètes $\mathrm{d}^{\prime} A R N m$ ?

9) Les molécules incomplètes d'ARNm sont-elles stables à l'intérieur des LPNs et à l'intérieur de I'hôte vaccinée ? 
10) Les molécules incomplètes d'ARNm sont-elles traduites en polypeptides dans l'hôte vacciné ?

11) Quel est le sort des polypeptides produits à partir de molécules incomplètes d'ARNm qui sont stables et traduites dans la cellule hôte?

Nous n'avons pas encore vu d'études publiées sur ces sujets. Mais étant donné la complexité et l'efficacité de notre biochimie, il est possible que nos cellules puissent gérer les situations éventuelles. Sinon, cela poserait-il un problème à long terme de toxicité cellulaire et génomique, surtout si le vaccin doit être pris à plusieurs reprises ? Nous avons déjà soulevé ces questions et nous attendons le retour de toute personne ayant une réponse suffisante et convaincante (25-28).

Nous suggérons les expériences préliminaires suivantes pour répondre à ces questions. Le premier type d'expérimentation consisterait à déterminer si le produit d'une synthèse in vitro d'ARNm à partir d'une matrice d'ADN sans cellules, contient des molécules d'ARNm dont l'élongation a été faite sur le carbone C 2-prime. Le cas échéant, quelle proportion ce type de molécules représente-t-il dans le mélange ? Le deuxième type 
d'expériences consisterait à bloquer le carbone C3-prime et à synthétiser un ARNm par élongation uniquement sur le carbone C2-prime. Le troisième type d'expériences consisterait à injecter cet ARNm C2-prime dans des cultures cellulaires et à mesurer son effet toxique. Le marquage du C2-prime ou du C3-prime peut être un moyen de surveiller la synthèse de l'ARNm in vitro (25 - 28).

Les développeurs de vaccins à $A R N m$ ont peut-être déjà réalisé ces expériences car ils ont dû montrer des études de biocompatibilité pour obtenir l'approbation des autorités de régulation. Ou peut-être que des universitaires et d'autres groupes indépendants ont mené des recherches dans ce domaine. Si tel est le cas, prière de partager avec nous vos découvertes.

\section{Un vaccin génétique peut-il induire ou aggraver des maladies auto-immunes?}

Oui, c'est possible, mais de telles complications ne seraient pas observées uniquement avec les vaccins génétiques. En théorie, elles peuvent survenir avec n'importe quel vaccin. Pour qu'un vaccin déclenche ou exacerbe une réponse auto-immune, il doit tromper notre système immunitaire et le rendre incapable de 
distinguer entre le soi et le non-soi. Les maladies auto-immunes se développent lorsque les lymphocytes-T auto réactifs réussissent à échapper le contrôle des étapes de maturation ainsi que la suppression par le système immunitaire (29).

Cependant, de nombreuses études ont montré la présence d'auto-anticorps dans les sérums de patients infectés par SRAS-Cov-2 (70 - 84). Certains de ces anticorps et les maladies auxquelles ils sont associés sont répertoriés dans le Tableau-2 ci-dessous.

Le vaccin peut-il provoquer des maladies auto-immunes similaires à celles causées par l'infection naturelle?

Les vaccins dirigés contre les protéines de SRAS-Cov-2 telles que la protéine-S provoquent la production d'anticorps qui bloquent le domaine peptidique utilisé par la protéine-S pour s'ancrer à la membrane cytoplasmique des cellules hôtes, au niveau du récepteur ACE-2. Ces vaccins activent aussi des sous-classes de lymphocytes-T qui confèrent une réponse immunitaire cellulaire. Il est nécessaire de rechercher si les anticorps produits, ou les sous-classes de lymphocytes- $T$ activées par ces vaccins, réagissent ou non de manière croisée 
avec les domaines peptidiques de l'Angiotensine-Il et donc la bloquent également ? Si une telle possibilité existe, même à un niveau minimal, les conséquences pour notre santé seraient très graves étant donné le rôle important de l'Angiotensine-II dans notre physiologie. La même question peut être étendue à tous les autres vaccins utilisant d'autres protéines SRAS-Cov-2 telles que la protéine- $M$, et à toutes les protéines humaines connues.

Nous proposons les expériences préliminaires suivantes pour tenter de répondre à ces questions. A partir du génome de SRAS-Cov-2, on peut déduire les séquences d'acides aminés de l'ensemble de ses protéines comme la protéine-S dont l'ARNm est utilisé dans les vaccins déjà disponibles sur le marché. Les séquences d'acides aminés de nombreuses protéines humaines peuvent également être obtenues à partir de la base de données du projet du Génome Humain. 


\begin{tabular}{|c|c|}
\hline Table-2 & \\
\hline Autoimmine antibodiess & Autoimmune diseases \\
\hline Anti Nuclear Antibodies (ANA) & Systemic Lupus Erythematosus, Sjogren Syndrome, Scleroderma, Rheumatoid arthritis \\
\hline Anti- $\beta 2$ Glycoprotein I (Anti- $\beta 2$ GPI) & Anti-Phoslipid Syndrome (thrombosis, thrombocytopenia, obstetric complications) \\
\hline Anti-Angiotensin Converting Enzyme 2 (Anti-ACE-2) & Constructive vasculopathies \\
\hline Anti-Annexin V & Systemic Lupus Erythematosus, Rheumatoid arthritis, Anti-Phoslipid Syndrome, Thrombosis \\
\hline Anti-Cardiolipin & Systemic Lupus Erythematosus, Rheumatoid arthritis, Anti-Phoslipid Syndrome, Vasculitis \\
\hline Anti-Contactin Associated Protein 2 (Anti-CASPR 2) & Encephalitis, Epilepsy, Ataxia, Neuropathic pain, Morvan's Syndrome, Isaac's Syndrome, Psychoses \\
\hline Anti-Cyclic Citrulinated Peptides (Anti-CCP) & Rheumatoid arthritis \\
\hline Anti-Heparin PF4 & Thrombocytopenia, Veinous Thrombosis \\
\hline Anti-Muscle Specific Kinase (Anti-MuSK) & Myastenia Gravis \\
\hline Anti-Phosphatidylserine & Anti-Phospholipid syndrome, Venous Thrombosis, ST-levation Myocardial Infarction \\
\hline Anti-Prothrombin & Anti-Phospholipid syndrome (thrombosis, thrombocytopenia, obstetric complications) \\
\hline Anti-Ro52 & Myositis, Scleroderma, Liver diseases, interstitial lung disease, Connective Tissue Diseases \\
\hline Anti-Ro60 & Systemic Lupus Erythematosus, Sjogren Syndrome, Rheumatoid arthritis \\
\hline Anti-Type I Interferons (Anti-IFNs) & Spread of Microbial Infections \\
\hline Cytoplasmic Anti-Neutrophil Cytoplasmic Antibodies (C-ANCA) & Immunodeficiency, Vasculitis, Glomerulonephritis, Cholangitis, Inflammatory Bowel Disease \\
\hline Lupus Anti-Coagulant (LAC) & Anti-Phoslipid Syndrome (thrombosis, thrombocytopenia, obstetric complications) \\
\hline Perinuclear Anti-Neutrophil Cytoplasmic Antibodies (P-ANCA) & Glomerulonephritis, Polyarteritis Nodosa, Churg-Strauss Syndrome, polyangitis \\
\hline \multirow[t]{6}{*}{ Rheumatoid Factor } & Rheumatoid Arthritis, Sjogren Syndrome, Viral infections \\
\hline & Auto Immune Haemolytic Anemia \\
\hline & Guillain Barré Syndrome \\
\hline & Immune Thrombocytopenic Purpura \\
\hline & Kawasaki Disease \\
\hline & Miller Fisher Syndrome \\
\hline
\end{tabular}


Par conséquent, il est facile de déterminer le degré d'homologie entre les protéines de SRAS-Cov-2 et les protéines humaines connues. On sait également que la réponse immunitaire induite par l'infection naturelle par SRAS-Cov-2, ou provoquée par le vaccin, est à la fois humorale et cellulaire. Des expériences rapides consisteraient à déterminer si les sérums de patients qui ont contracté l'infection naturelle ou qui ont été vaccinés réagissent avec des protéines humaines qui présentent des homologies avec les protéines de SRASCov-2. Des expériences plus détaillées et laborieuses consisteraient d'abord à isoler et cataloguer les anticorps produits ainsi que les sous-classes de lymphocytes- $T$ activés, à partir de patients naturellement infectés ainsi que de patients vaccinés. Deuxièmement, les domaines antigéniques reconnus respectivement par ces anticorps et ces sous-classes de lymphocytes-T activés sont cartographiés sur les protéines de SARS-Cov-2. Nous pourrions alors rechercher si ces domaines antigéniques reconnus existaient également sur les protéines humaines et s'ils étaient également reconnus. Une réaction croisée contre des protéines humaines suggérerait la possibilité de réactions auto-immunes $(25$ - 28). 
Comme nous l'avons expliqué ci-dessus, les virus à $A R N$ mutent fréquemment. Ce processus peut générer des mutants plus infectieux, plus virulents, plus résistants aux traitements et aux vaccins, plus trompeurs et déroutants pour le système immunitaire, et peut-être plus mortels. Plusieurs chercheurs ont rapporté la détection d'autoanticorps chez des patients naturellement infectés (49 - 60, 70 - 84). Les vaccins provoqueraient-ils des maladies auto-immunes en provoquant des auto-anticorps et / ou des sous-classes de lymphocytes-T à réactivité croisée ? Seul le temps le dira.

Les développeurs de vaccins à $A R N m$ ainsi que les instances de régulation se sont peut-être déjà posés les mêmes questions et ont probablement des réponses confidentielles. En fin de compte, il s'agit de faire confiance au processus de contrôle du système redondant sur le rapport bénéfice / risque de se faire vacciner.

\section{Les vaccins auront-ils des conséquences à long terme sur notre santé ?}

L'ARNm utilisé dans le vaccin est synthétisé in vitro plutôt que produit biologiquement. Par conséquent, il est beaucoup plus rapide à produire que les vaccins conventionnels. La technologie des vaccins à $A R N m$ n'est pas 
nouvelle. C'était dans le développement pendant des décennies. Étant donné que l'ARNm se dégrade facilement à température ambiante, la progression a été très lente. En 2005, des chercheurs ont découvert que le conditionnement de l'ARNm dans de petites particules lipidiques appelées LPNS ou micelles augmentait sa stabilité. Ainsi, l'utilisation de l'ARNm dans le développement de vaccins est devenue un objectif réalisable. Les micelles peuvent fusionner avec la membrane cellulaire de la cellule hôte et avec la membrane endosomique pour libérer leur contenu d'ARNm dans le cytoplasme des cellules hôtes où l'ARNm est traduit par la machinerie cellulaire pour produire la protéine encodée par l'ARNm (Fig-2). Les questions que nous nous sommes posées à ce niveau ont été détaillées ci-dessus et ailleurs. (25-28).

\section{Que disent les promoteurs de la sécurité des vaccins à ARNm ?}

La sécurité est la première préoccupation dans l'esprit de beaucoup, y compris les professionnels de la santé (34). Par conséquent, la question de la sécurité a été analysée, étudiée et examinée. Les arguments présentés en faveur de l'innocuité des vaccins à $A R N m$ anti-SRAS-Cov-2 incluent l'expérience cumulée avec ce type de 
vaccins (39-41), les tests minutieux du vaccin suivant toutes les étapes requises dans les essais cliniques (17), le recrutement d'un grand nombre d'individus pour participer aux essais cliniques, L'établissement d'intervalles de temps courts pour les fabricants de communiquer de façon régulière leurs données aux autorités de régulation, et la surveillance en permanence des effets secondaires chez les individus vaccinés (36). De plus, le temps relativement court consacré à la mise au point de ces vaccins était dû au type de technologies utilisées et en aucun cas à des sauts d'étapes de sécurité ou à un manque de vigilance vaccinale ou de pharmacovigilance (35). En outre, le vaccin est synthétisé in vitro sans culture cellulaire et est donc ne contient pas de contaminants cellulaires et ne provoque pas plus d'allergies (42). Enfin, des études animales ont montré que l'ARNm est rapidement dégradé (37) et reste localisé dans la zone où il est injecté (38).

\section{Que disent les critiques des vaccins anti-SRAS-Cov-2 ?}

De nombreux groupes sont contre la vaccination en général. Ils affirment que les vaccins provoquent des troubles chroniques tels que l'autisme, le diabète, l'asthme, les allergies et plusieurs maladies auto-immunes. 
Ils critiquent la façon dont les essais cliniques sont conçus, exécutés et analysés. Ils pensent que les produits vaccinaux sont testés sur de petits groupes de volontaires non représentatifs de la population, que les données de sécurité sont collectées sur une courte période qui ne permet pas de détecter les effets secondaires à développement lent tels que les maladies auto-immunes et dégénératives chroniques. Ils insistent sur le fait qu'un essai clinique approprié doit inclure au moins 500000 individus et un suivi des effets secondaires d'au moins 7 ans.

Un article récent publié par un critique de la vaccination bien connu suggère que les molécules d'ARNm utilisées dans les vaccins anti-SRAS-Cov-2 contiennent des séquences qui peuvent être reconnues par des protéines intrinsèques telles que TAR-DNA-binding-Protein-43 (TDP -43) et la protéine de fusion en sarcome (FUS). L'auteur suggère que cette interaction induit la conversion de ces protéines en prions. En outre, il a théorisé que l'agrégation du TDP-43 et FUS dans leurs conformations pathologiques serait à l'origines de maladies neurodégénératives telles que la maladie d'Alzheimer et la sclérose latérale amyotrophique (SLA). Il ajoute que 
I'interaction de la protéine-S de SRAS-Cov-2 avec le récepteur ACE-2 amènerait l'Angiotensine -II à décharger ses molécules de zinc, ce qui induirait le TDP-43 à assumer son état pathologique de prion. De plus, l'auteur évoque la controverse à propos de l'origine de SRAS-Cov-2. II suggère que si le SRAS-Cov-2 était une arme biologique fabriquée par l'homme, alors les vaccins à base de la protéine-S mettraient l'humanité en danger dans le cas où une seconde attaque utilise un pathogène guidé par la protéine-S. Enfin, l'auteur prévient que, quelle que soit la cause de l'infection naturelle, les effets de celle-ci seraient moins étendus que ceux causés par un vaccin qui va être administré à un plus grand nombre de personnes dans le monde (48).

\section{Les vaccins anti-SRAS-Cov-2 vont-ils protéger contre tous les mutants viraux?}

C'est possible mais à u certain degré parce que la variabilité génétique de SRAS-Cov-2 est bien inférieure à celle d'autres virus pour lesquels nous disposons déjà de vaccins efficaces comme le virus de la grippe, la rougeole, le virus de l'hépatite $\mathrm{B}$, les oreillons, l'Ebola, etc. De plus, le vaccin réduira la transmission des mutants dans la population. 
Cependant, il existe également des rapports publiés qui montrent que le vaccin Pfizer / BioNTech (BNT162b2) produit deux tiers d'anticorps neutralisants en moins contre un mutant de laboratoire imitant le variant SARSCov-2 sud-africain B.1.351 (47). D'autres études sont nécessaires pour comprendre ce qui a provoqué la baisse dans la production d'anticorps neutralisants. Est-ce le vaccin ? ou est-ce le mutant viral ?

Après avoir lancé des campagnes de vaccination dans de nombreux pays, le débat concernant l'efficacité des vaccins anti-SRAS-Cov-2 contre le variant sud-africain B.1.351, le variant brésilien P.1, le variant britannique B.1.1.7 (67) et d'autres variants futurs, s'est intensifié (47). Une solution à l'émergence de variants de SRAS-Cov2 qui sont résistants aux vaccins actuels composées de molécules homogènes d'ARNm qui encodent pour le type sauvage de la protéine-S serait le développement de nouveaux vaccins constitués d'un mélange hétérogène de molécules d'ARNm qui encodent pour le type sauvage et les différents types mutés de la protéine-S.

Une telle tâche serait rapidement accomplie par l'industrie pharmaceutique car la technologie impliquée est facilement adaptable et rapidement mise en œuvre. La proportion de chaque type de molécules d'ARNm dans 
le mélange de vaccins serait optimisée pour susciter une immunité protectrice contre le type sauvage de SRASCov-2 et ses mutants (68).

\section{Le vaccin résoudra-t-il tous les problèmes?}

Non. Le vaccin protège déjà contre les formes sévères d'infections de SRAS-Cov-2 et c'est déjà un grand pas en avant. Mais le vaccin ne répondra pas à tous nos challenges. Premièrement, les vaccins ont été essayés uniquement sur des adultes et non pas sur des enfants. Deuxièmement, on ne sait pas si les vaccins vont empêcher la transmission de l'infection et s'ils conféreront une immunité collective. Nous ne connaissons pas l'impact des différentes pathologies et traitements sur la réponse immunitaire aux vaccins et nous ne connaissons pas leur efficacité chez les personnes âgées, et chez les enfants âgés de moins de 16 ans.

La solution peut être dans le développement d'anticorps thérapeutiques qui à la fois neutralisent le virus circulant et stimulent les cellules immunitaires pour phagocyter le virus et produire une immunité protectrice (14). 
Doit-on continuer les précautions de sécurité après la vaccination ?

Oui. Le vaccin protège contre les formes sévères de l'infection mais n'arrête pas la réinfection ou la transmission du virus.

Tous les vaccins en cours de développement produisent-ils le même effet?

Non. Une étude expérimentale a montré que les souris vaccinées avec de l'ARNm produisaient une réponse immunitaire plus robuste en termes de cellules immunitaires à mémoire B à longue durée de vie et d'anticorps neutralisants que les souris vaccinées avec la protéine-S plus adjuvant. II apparaît également que les vaccins à base d'ARNm ou de virus génétiquement modifiés induisent des réponses immunitaires humorales et cellulaires protectrices contre les formes sévères d'infection de SARS-Cov-2 (95\% et 90\% d'efficacité), contrairement aux vaccins à base de protéines et d'adjuvants (13). 


\section{À quoi ressemble le vaccin ARNm ?}

Le vaccin ne se présente pas en une seule dose dans une seringue préremplie comme les autres vaccins que vous utilisez. Les vaccins anti-SARS-Cov-2 à base d'ARNm sont fournis dans des flacons multidoses. Une dose de $0,5 \mathrm{ml}$ contient, selon les producteurs, de 30 à $100 \mu \mathrm{g}$ d'ARNm simple brin qui encode pour la protéine-S de SRAS-Cov-2. L'ARNm a été synthétisé in vitro à partir d'une matrice d'ADN, sans cellules, et encapsulé dans des nanoparticules lipidiques ( $L P N s)$, puis ajouté à une suspension de phospholipides, cholestérol, polyéthylène glycol, trométamol, acide acétique, acétate de sodium, saccharose et eau (Fig-2).

\section{Ya-t-il des effets secondaires immédiats?}

Oui, mais à basse fréquence. Les personnes vaccinées ont principalement signalé une fatigue, des maux de tête, des nausées, des douleurs musculaires et articulaires, des douleurs et / ou un gonflement et / ou des démangeaisons au site d'injection et de la fièvre ou des frissons. Ces effets indésirables étaient plus sévères chez les patients jeunes que chez les personnes âgées, et après la deuxième injection que la première (15). 
D'autres effets indésirables ont également été rapportés tels que syncope, essoufflement, modification de la fréquence cardiaque, gonflement des lèvres ou du visage, inconfort dans la gorge, éruption cutanée, urticaire, douleurs à l'estomac et vomissements. Les effets rares rapportés incluent la paralysie faciale, l'hypersensibilité au vaccin et les réactions allergiques sévères d'anaphylaxie.

\section{Les patients qui ont une condition particulière devraient-ils recevoir le vaccin ARNm ?}

Le Centre de Contrôle et de Prevention des Maladies (CDC) a publié le $\mathbf{1 0}$ février $\mathbf{2 0 2 1}$ des considérations provisoires pour l'utilisation des vaccins à ARNm actuellement autorisés aux États-Unis d'Amérique (69). Ces considérations sont résumées dans le Tableau-3 ci-dessous. Le lecteur est invité à consulter le site-web du CDC pour les mises à jour, et les autorités locales de son pays pour des instructions spécifiques sur l'utilisation des vaccins à $A R N m$. 
Une deuxième dose du vaccin est-elle nécessaire pour avoir une immunité plus forte?

Peut-être pas. Un examen récent des données soumises à la FDA par Pfizer / BioNTech a montré que leur vaccin BNT162b2 était en fait très efficace avec une seule dose. Compte tenu de la pénurie mondiale de vaccins, les chercheurs ont proposé de retarder la deuxième dose jusqu'à ce que les personnes prioritaires aient reçu la première dose (35, 43 - 45). Dans sa réponse, Pfizer a déclaré ce qui suit : « Nous tenons à souligner que d'autres schémas posologiques de BNT162b2 n'ont pas été évalués. La décision de mettre en œuvre des schémas posologiques alternatifs appartient aux autorités sanitaires; cependant, chez Pfizer, nous pensons qu'il est essentiel que les autorités sanitaires mènent une surveillance sur les schémas posologiques alternatifs mis en œuvre pour garantir que les vaccins offrent la protection maximale possible » (46).

\section{Le vaccin devrait-il être obligatoire?}

Non, car le vaccin est décrit comme un outil qui protège contre les formes sévères de la maladie et non comme un outil qui empêche le transfert du virus d'une personne à une autre. Le patient doit donc conserver la liberté 


\begin{tabular}{|c|c|}
\hline Table-3 & \\
\hline Type of Situations you may have in your practice & What should you recommend to your patient about vaccination with mRNA vaccines? \\
\hline Known severe allergic reaction e.g. anaphylaxis & No \\
\hline Previous allergic reaction to an mRNA vaccine & No \\
\hline Hupersensitivity to Polyethylen glycol (PEG) & No \\
\hline Age group less than 16 years old & No \\
\hline Age group more than 16 but less tahn 18 years old & Pfizer/BioNTech \\
\hline Age group 18 years old or more & Pfizer/BioNTech or Moderna \\
\hline Coadministration with other vaccines & No. Minimum interval of 14 days. Except if the benifit of the second vaccine outweigh the risk \\
\hline Need for a booster beyond the two doses & Has not been established \\
\hline Testing for SARS-Cov-2 infection before vaccination & No need for testing. But patient should not have active symptoms \\
\hline Patient with prior SARS-Cov-2 infection & Yes, except patient should not have active symptoms \\
\hline Patient with active SARS-Cov- 2 infection & No. Wait until symptoms are completely resolved and patient has met the isolation requirements \\
\hline Patient who contracts SARS-Cov-2 after the first dose & Yes, but only after symptoms are completely resolved \\
\hline Pantient who received MoAntibodies or covalescente plasma & Yes, but after 90 days, except if the treatment received was not specific to Covid-19 treatment \\
\hline Patient who received MoAb or plasma after first dose & Yes, but wait for 90 days before giving the second dose, except if the treatment was not for Covid-19 \\
\hline Can I take the vaccine as a prophylaxis after exposure & No, because SARS-Cov- 2 has a short preincubation period of 4-5 days, thus, it would not be effective \\
\hline Congregate setting \& vaccinated after exposure & Yes, if the resident does not have symptoms. It is a different rule than for non congregate setting \\
\hline The immunocompromised patient & Yes, if there is no contraindication to vaccination. But, lack of data about safety and benefit \\
\hline I was vaccinated while taking immunosupressive treatment & No need for revaccination after treatment is stopped and immunocomptence is regained \\
\hline Patient with autoimmune conditions & Yes, But should be counseled about the lack of data about safety and efficacy \\
\hline Patient with Guillain Barré Syndrome & Yes, if no contradiction to vaccination \\
\hline Patient with Bell's palsy & Yes, if no contraindication to vaccination \\
\hline Patient who received injectable dermal filler & Yes, if no contradiction to vaccination \\
\hline Do I have to take a pregnancy test before taking the vaccine? & No recommendation \\
\hline I took the vaccine shoult I stop trying to get pregnant? & No need to avoid pregnancy \\
\hline I am pregnant should I take the vaccine? & Decision left to the patient after being couseled about the lack of safety data during pregnancy \\
\hline The Lactating patient & Decision left to the patient after being couseled about the lack of safety data during breast feeding \\
\hline
\end{tabular}


de décider pour sa santé et son corps. En revanche, si le vaccin protège contre la contagion et que nous ne pouvons pas contrôler autrement la propagation du virus, la vaccination obligatoire devient une option.

\section{Une carte de vaccination doit-elle être délivrée aux vaccinés ?}

Oui. La preuve d'être vacciné contre certaines maladies est déjà une obligation pour voyager dans certains pays. Mais, aucune de ces situations ne se compare tout à fait à celle de SRAS-Cov-2 qui affecte toute la planète. II existe donc un conflit entre le droit à la liberté de choix et les obligations qui peuvent être imposées en fonction de notre type de travail, de nos habitudes de déplacement et de notre profil d'activités sociales etc. Ces craintes sont susceptibles de motiver les gens à prendre le vaccin, même si être vacciné ne signifie pas être immunisé contre l'infection. Pour ceux d'entre nous qui ne peuvent pas se faire vacciner en raison de problèmes de santé graves, peut-être que l'isolement et la quarantaine sont la solution. 
Toutes ces questions sur les vaccins contre le SRAS-Cov2 sont-elles justifiées et pourquoi devons-nous examiner les vaccins lorsque le virus cause des conséquences pires pendant l'infection naturelle?

En un an, SRAS-Cov-2 a infecté près de 115 millions de personnes et tué près de 2,6 millions dans le monde. Bien que ces chiffres soient alarmants, ils représentent respectivement $1,44 \%$ et $0,0325 \%$ de la population mondiale estimée à 8 milliards. Par conséquent, un vaccin censé être administré à 70 à $80 \%$ de la population mondiale afin de maîtriser SRAS-Cov-2 doit faire l'objet d'un examen minutieux, car toute erreur grave pourrait causer des dommages qui dépassent de loin ce que l'infection naturelle par SRAS-Cov- 2 peut faire.

Nous sommes partisans de la vaccination qui est la couronne de la médecine moderne. Nous avons passé plusieurs années de notre vie à mener des recherches dans ce domaine (1 - 3). Cependant, même si les questions sont ennuyeuses, il faut y répondre de manière réfléchie. Les questions sur la sécurité de la vaccination contre SRAS-Cov2 peuvent être résolues scientifiquement sans se livrer à des spéculations injustifiées. On peut y répondre en menant des recherches fondamentales en immunologie, en biologie cellulaire et moléculaire, en 
microbiologie et en biochimie. Notre rôle en tant que scientifiques et praticiens de l'art de la guérison est de débattre ouvertement ces problèmes dans un environnement académique libre. L'industrie pharmaceutique et les agences de régulation pourraient alors être intéressées par le financement de ce type de recherche. II n'est pas acceptable que les médicaments destinés à être utilisés chez l'homme deviennent comme d'autres produits technologiques qui sont vendus aux consommateurs avant de corriger leurs défauts de conception puis de déléguer ensuite la gestion de ces problèmes à un service de clientèle.

L'industrie pharmaceutique est un acteur majeur de la santé. Nous sommes convaincus que ses scientifiques mènent leur recherche et développement avec diligence et veillent à ce que leurs produits soient sûrs et efficaces.

Remerciements : L'auteur remercie Sonia Chatellier, PhD., pour sa critique et ses commentaires, et Katarzyna Marciniak, MD., pour les illustrations et ses suggestions.

Conflit d'intérêts : l'auteur n'a aucun conflit d'intérêts 


\section{REFERENCES}

1- Labidi, A., (1986).

Contribution to a plan of action for research in molecular biology and immunology of mycobacteria, Ph.D. Thesis, University of Paris 7 - Pasteur Institute, Paris, France, (January 1986)

2- $\quad$ Labidi, A. (1988).

Mycobacterium recombinant vaccines.

Patents \# WO-1998-044096, PTC/US-98/06056, US-09402146, AU-1998067804, BRP-19808441, CA-2284736, EP-0973881, JP-2001518781, MXPA-a-1999-008868, 228473

3- $\quad$ Labidi, A., et al. (2001)

Mycobacterium recombinant vaccines.

Tun. Med., 79(2), 65-81, (2001)

4- $\quad$ Leskovar, A., et al. (2000).

The macrophage in acute neural injury: changes in cell numbers over time and levels of cytokine production in mammalian central and peripheral nervous systems

J. Exp. Biol. 203, 1783-1795, (2000)

5- Grange, J. M., and Stanford, J. L. (1996).

Therapeutic vaccines. 
J. Med. Microbiol. 45, 81-83, (1996)

6- Grange, J. M., et al. (1995)

Tuberculosis and Cancer: parallels in host responses and therapeutic approaches.

The Lancet. 345, 1350-1352, (1995)

7- $\quad$ Stanford, J. L., and Rook, G. A. W. (1997)

Mycobacterium as adjuvant for antigens.

Patent \# US 005599545, (1997)

8- Wei Lin, et al. (2020)

The disease stage-associated imbalance of Th1/Th2 and Th17/Treg in uterine cervical cancer patients and their recovery with the reduction of tumor burden

BMC Women's Health, 20 (126), (2020)

9- Cevik M., et al. (2020)

Virology, transmission, and pathogenesis of SARS-CoV-2

BMJ 371:m3862, (2020)

https://doi.org/10.1136/bmj.m3862

10- Lumley S. F., et al. (2020)

Antibodies to SARS-CoV-2 are associated with protection against reinfection. 
https://doi.org/10.1101/2020.11.18.20234369

11- Dan J.M, et al. (2020)

Immunological memory to SARS-CoV-2 assessed for up to eight months after infection. https://www.biorxiv.org/content/10.1101/2020.11.15.383323v1

12- Hotez P. J., et al. (2020)

COVID-19 vaccine design: the Janus face of immune enhancement

Nature Rev. Immunol., 20, 347-348 (2020)

13- Ledrer K., et al. (2020)

SARS-CoV-2 mRNA Vaccines Foster Potent Antigen-Specific Germinal Center Responses Associated with Neutralizing Antibody Generation.

https://doi.org/10.1016/j.immuni.2020.11.009

14- Chen P., et al. (2020)

SARS-CoV-2 Neutralizing Antibody LY-CoV555 in Outpatients with Covid-19

https://www.nejm.org/doi/full/10.1056/NEJMoa2029849 
15- The Advisory Committee on Immunization Practices (ACIP), Centers for Disease Control and Prevention (CDC), December 20, 2020 Interim Clinical Considerations for Use of mRNA COVID-19 Vaccines Currently Authorized in the United States

https://www.cdc.gov/vaccines/covid-19/info-by-product/clinical-considerations.html

16- Huang Y., et al. (2020)

Structural and functional properties of SARS-CoV-2 spike protein: potential antivirus drug development for COVID-19

Acta Pharm. Sinica,41, 141-1149, (2020)

17- Krammer F., (2020)

SARS-CoV-2 vaccines in development

Nature, 586, 516-527, (2020)

18- Corbett K. S., et al. (2020)

SARS-CoV-2 mRNA vaccine design enabled by prototype pathogen preparedness.

Nature, 586, 567-571, (2020)

19- Bélanger F., et al. (2010)

Characterization of hMTr1, a Human Cap1 2'-O-Ribose Methyltransferase

J. Biol. Chem., 285 (43), 33037-33044, (2010) 
20- Labidi, A., (2020)

A new protocol for a potential treatment of infections due to SARS-Cov-2

https://doi.org/10.31219/osf.io/jhksx, https://www.researchgate.net/publication/340322772

21- Pardi N., et al. (2018)

$m R N A$ vaccines - a new era in vaccinology

Nature Rev. Drug Discov., 17(4), (2018)

22- Duan L., et al. (2020)

The SARS-CoV-2 Spike Glycoprotein Biosynthesis, Structure, Function, and Antigenicity: Implications for the Design of Spike-Based Vaccine Immunogens

Front. Immunol., October 07, (2020) https://doi.org/10.3389/fimmu.2020.576622

23- Masters P. S., (2019)

Coronavirus genomic RNA packaging

Virology, 537, 198-207, (2019)

24- Eleni Nikolakaki and Thomas Giannakouros (2020)

SR/RS Motifs as Critical Determinants of Coronavirus Life Cycle

Front Mol Biosci., 7, 219, (2020) 
25- Labidi A.

The safety of $m R N A$ vaccines targeting the spike protein of SARS-Cov2.

ResearchGate: https://www.researchgate.net/publication/349061518

License: $\underline{\text { CC BY-NC-SA } 4.0}$

26- Labidi A., (2021)

The safety of vaccines targeting SARS-Cov2 proteins

ResearchGate: https://www.researchgate.net/publication/349290494

License : CC BY-NC-SA 4.0

27- Labidi A., (2021)

La sécurité des vaccins à ARNm ciblant la protéine de spécule de SRAS-Cov2

ResearchGate: https://www.researchgate.net/publication/349061716

License : CC BY-NC-SA 4.0

28- Labidi A., (2021)

La sécurité des vaccins ciblant les protéines de SRAS-Cov2

ResearchGate: https://www.researchgate.net/publication/349290667

License: CC BY-NC-SA 4.0 
29- Kisielow, $\mathrm{P}$.

How does the immune system learn to distinguish between good and evil? The first definitive studies of T cell central tolerance and positive selection.

Immunogenetics 71, 513-518 (2019)

https://doi.org/10.1007/s00251-019-01127-8

30- Ozawa S., et al. (2016)

Return on investment from childhood immunization in low- and middle-income Countries, 2011-20

Health Affairs, 35(2):199-207, (2016)

doi: $10.1377 /$ hlthaff.2015.1086

31- Nørgaard S. K., et al., (2021)

Real-time monitoring shows substantial excess all-cause mortality during second wave of COVID-19 in Europe,

October to December 2020

Euro Surveill., 26(2), (2021)

https://doi.org/10.2807/1560-7917.ES.2021.26.1.2002023

32- Sridhar D., and Gurdasani D., (2021)

Herd immunity by infection is not an option.

Science, 371 (6526), 230-231, (2021)

doi : $10.1126 /$ science.abf7921 
33- Rausch J. W., et al (2020)

Low genetic diversity may be an Achilles heel of SARS-CoV-2

Proc Natl Acad Sci U S A., 117(40), 24614-24616, (2020)

doi: $10.1073 /$ pnas.2017726117

34- Verger P., et al. (2021)

Attitudes of healthcare workers towards COVID-19 vaccination: a survey in France and French-speaking parts of Belgium and Canada, 2020

Euro. Surv. 26(3), (2021)

https://doi.org/10.2807/1560 7917.ES.2021.26.3.2002047

35- Puthumana P., et al. (2020)

Speed, Evidence, and Safety Characteristics of Vaccine Approvals by the US Food and Drug Administration JAMA Intern Med .Published online November 10, (2020) doi:10.1001/jamainternmed.2020.7472

36- Polack F. P., et al. (2020)

Safety and Efficacy of the BNT162b2 mRNA Covid-19 Vaccine

NEJM, 383(27), 2603-2315, (2020)

doi : $10.1056 /$ NEJMoa2034577

37- Wolf J. A., et al. (1990)

Direct gene transfer into mouse muscle in vivo

Science, 247(4949 Pt 1), 1465-1468, (1990)

doi : 10.1126/science.1690918. 
38- Lindsay K. E., et al (2019)

Visualization of early events in $m R N A$ vaccine delivery in non-human primates via PET-CT and near-infrared imaging

Nature Biomedical Engineering, 3, 371-380, (2019)

39- Feldman R. A., et al (2019)

$m R N A$ vaccines against $\mathrm{H} 10 \mathrm{~N} 8$ and $\mathrm{H} 7 \mathrm{~N} 9$ influenza viruses of pandemic potential are immunogenic and well tolerated in healthy adults in phase 1 randomized clinical trials.

Vaccine, 37 (25), 3326-3334, (2019)

doi : $10.1016 /$ j.vaccine.2019.04.074

40- Alberer M., et al (2017)

Safety and immunogenicity of a $m R N A$ rabies vaccine in healthy adults: an open-label, non-randomized, prospective, first-in-human phase 1 clinical trial

Lancet, 390(10101), 1511-1520, (2017)

doi : $10.1016 / \mathrm{S} 0140-6736(17) 31665-3$

41- Mutua G., (2019)

Safety and Immunogenicity of a 2-Dose Heterologous Vaccine Regimen with Ad26.ZEBOV and MVA-BN-Filo Ebola Vaccines: 12-Month Data from a Phase 1 Randomized Clinical Trial in Nairobi, Kenya

J Infect Dis, 220(1),57-67, (2019)

doi : 10.1093/infdis/jiz071 
42- Shimabukuro T., and Nair N., (2021)

Allergic Reactions Including Anaphylaxis After Receipt of the First Dose of Pfizer-BioNTech COVID-19 Vaccine JAMA, (2021)

doi:10.1001/jama.2021.0600

43- Skowronski D. M., and De Serres G., (2021)

Safety and Efficacy of the BNT162b2 mRNA Covid-19 Vaccine

Letter to the editor, NEJM, Feb 17, (2021)

doi: 10.1056/NEJMc2036242

44- Pfizer-BioNTech COVID-19 vaccine (BNT162, PF-07302048).

Vaccines and Related Biological Products Advisory Committee briefing document. December 10, (2020)

https://www.fda.gov/media/144246/download

45- Vaccines and Related Biological Products Advisory Committee meeting. December 17, (2020), FDA briefing document: Moderna COVID-19 vaccine

https://www.fda.gov/media/144434/download

46- Judith Absalon, et. al. (2021), Pfizer Pearl River, NY.

The authors reply: doi: 10.1056/NEJMc2036242

47- Yang Liu, et al., (2021)

Neutralizing Activity of BNT162b2-Elicited Serum - Preliminary Report 
NEJM February 17, 2021

doi: $10.1056 /$ NEJMc2102017

48- Classens J. B., (2021)

Covid-19 RNA based vaccines and risk of prion disease.

Microbiol. Infec. Dis., 5(1), 1-3, (2021)

49- Amiral J., (2020)

Can COVID-19 Induce an autoimmune disease associated with long- lasting symptoms and delayed complications?

Ann. Clin. Immunol. Microbiol., 2, 1014, (2020)

50- Wang EY., et al., (2020)

Diverse functional autoantibodies in patients with COVID-19.

medRxiv preprint. (2020)

51- Lyons-Weiler J., (2020)

Pathogenic priming likely contributes to serious and critical illness and mortality in COVID-19 via autoimmunity.

J.Transl. Autoimm., 3, 100051, (2020)

52- George Tetz and Victor Tetz, (2020)

SARS-CoV-2 prion-like domains in spike proteins enable higher affinity to ACE2.

www.preprints.org 


\section{doi: 10.20944/preprints202003.0422.v1}

53- Young MJ, et al., (2020)

Creutzfeldt-Jakob disease in a man with COVID-19: SARS-CoV-2-accelerated neuro degeneration?

Brain, Behavior, and Imm., 89, 601-603, (2020)

54- Galeotti C and Bayry J., (2020)

Autoimmune and inflammatory diseases following COVID-19.

Nat. Rev. Rheumatol. 1-2., (2020)

55- Zhang Y, et al., (2020)

Coagulopathy and antiphospholipid antibodies in patients with covid-19.

N. Engl. J. Med., 382(17), 38, (2020)

56- Caso F., et al., (2020)

Could Sars-coronavirus-2 trigger autoimmune and/or autoinflammatory mechanisms in genetically predisposed subjects?

Autoimm. Rev., 19(5), 102524, (2020)

57- Gazzaruso C., et al., (2020)

High prevalence of antinuclear antibodies and lupus anticoagulant in patients hospitalized for SARS-CoV2 pneumonia.

Clin. Rheumatol., 39(7), 2095-2109, (2020) 
58- Lerma L. A., et al (2020)

Prevalence of autoantibody responses in acute coronavirus disease 2019 (COVID-19)

J.Transl. Autoimm., 3, 100073, (2020)

59- Novelli L., et al., (2021)

The JANUS of chronic inflammatory and autoimmune diseases onset during COVID-19 - A systematic review of the literature

J. autoimm., 117, 102592, (2021)

60- McGarty T. P., (2021)

COVID-19: AUTOANTIBODIES The impact of COVID antigens on the immune system as sequalae https://www.researchgate.net/publication/348860153

doi: 10.13140/RG.2.2.30971.64808

61- Samad N., et al (2020)

Convalescent Plasma Therapy for Management of COVID-19: Perspectives and Deployment in the Current Global Pandemic

Risk Management and Healthcare Policy, 13, 2707-2728, (2020)

Doi: https://doi.org/10.2147/RMHP.S281388

62- Agarwal A., et al., (2020)

PLACID Trial Collaborators. Convalescent plasma in the management of moderate covid-19 in adults in India: open-label phase II multicenter randomized controlled trial (PLACID Trial). 
B.M.J., 371:m3939, 22 October (2020)

doi: http://dx.doi.org/10.1136/bmj.m3939

doi : https://www.researchgate.net/publication/344862351

63- Vahedi F., et al., (2012)

Investigation of DNA integration into reproductive organs following intramuscular injection of DNA in mice.

Rep. Biochem. Mol. Biol., 1(1), 21-24, (2012)

64- David R. M., and Doherty A. T., (2017)

Viral Vectors: The Road to Reducing Genotoxicity

Toxicol. Scien., 155 (2), 315-325, (2017)

https://doi.org/10.1093/toxsci/kfw220

65- Goswami R., et al. (2019)

Gene Therapy Leaves a Vicious Cycle

Front. Oncol., 9, 297, (2019)

doi: 10.3389/fonc. 2019.00297

66- Lundstrom K., (2020)

Application of Viral Vectors for Vaccine Development with a Special Emphasis on COVID-19

Viruses, 12, 1324, (2020)

doi:10.3390/v12111324 
67- Centers for Disease Control and Prevention (CDC), USA.

SARS-CoV-2 Variants

Updated Jan. 31, 2021

https://www.cdc.gov/coronavirus/2019-ncov/cases-updates/variant-surveillance/variant-info.html

68- Labidi A., (2021)

What if SARS-Cov-2 variants become resistant to current $m R N A$ vaccines?

https://www.researchgate.net/publication/349484209

DOI: $10.13140 / R G .2 .2 .33719 .24485$

69- Centers for Disease Control and Prevention (CDC), USA.

Interim Clinical Considerations for Use of $m R N A$ COVID-19 Vaccines Currently Authorized in the United States February 10, 2021

https://www.cdc.gov/vaccines/covid-19/info-by-product/clinical-considerations.html

70- Ehrenfeld M, at al., (2020)

Covid-19 and autoimmunity.

Autoimm. Rev., 19(8), 102597, (2020)

doi: $10.1016 /$ j.autrev.2020.102597

71- Sheifeld J, and Arad D, (2021)

Corona virus and autoimmune diseases

IMAJ, 23, 62-67, (2021) 
72- Yamelie A. M., et al., (2021)

The analysis on the human protein domain targets and host-like interacting motifs for the MERS-CoV and SARSCoV/CoV-2 infers the molecular mimicry of coronavirus.

PLoS One, 16(2), e0246901, (2021)

doi: $10.1371 /$ journal.pone.0246901

73- Kanduc D, and Shoenfeld Y., (2020)

Molecular mimicry between SARS-CoV-2 spike glycoprotein and mammalian proteomes: implications for the vaccine.

Immunol. Res., 68, 310-313, (2020)

doi: $10.1007 / \mathrm{s} 12026-020-09152-6$

74- Tan C. W, at al., (2020)

Critically ill COVID-19 infected patients exhibit increased clot waveform analysis parameters consistent with hypercoagulability.

Am. J. Hematol., 95(7), 156-158, (2020)

doi: $10.1002 /$ ajh.25822

75- Xiao M, at al., (2020)

Brief report: Anti- phospholipid antibodies in critically ill patients with coronavirus disease 2019 (COVID-19).

Arthr. \& Rheum.,72(12), 1998-2004, (2020)

doi: $10.1002 /$ art.41425 
76- Bertin D, at al., (2020)

Anti-cardiolipin IgG autoantibodies are an independent risk factor of COVID-19 severity.

Arthr. \& Rheum., 73(1), 1953-1955, (2020)

https:// doi.org/10.1002/art.41409

77- Bowles L, at al., (2020)

Lupus anticoagulant and abnormal coagulation tests in patients with Covid-19.

N. Engl. J. Med., 383(3), 288-290, (2020)

doi: $\underline{10.1056 / N E J M c 2013656}$

78- Vlachoyiannopoulos G, at al., (2020)

Autoantibodies related to systemic autoimmune rheumatic diseases in severely ill patients with COVID-19.

Ann. Rheum. Dis., 79(12), 1661-1663, (2020)

http://dx.doi.org/10.1136/annrheumdis-2020-218009

79- Akca K, at al., (2020)

Kawasaki-like disease in children with COVID-19.

Rheum. intern., 40(12), 2105-2115, (2020)

https://doi.org/10.1007/s00296-020-04701-6

80- Rahimi K., (2020)

Guillain-Barre syndrome during COVID-19 pandemic: an overview of the reports.

Italian Neuro. Sci., 41(11), 3149-3156, (2020)

https://doi.org/10.1007/s10072-020-04693-y 
81- Zulfiqar A, at al., (2020)

Immune thrombocytopenic purpura in a patient with Covid-19

N. Engl. J. Med., 382(18), e43, (2020)

doi: $10.1056 /$ NEJMc2010472

82- Mantovani E, at al., (2020)

Concomitant new diagnosis of systemic lupus erythematosus and COVID-19 with possible antiphospholipid syndrome. Just a coincidence? A case report and review of intertwining pathophysiology.

Clin. Rheum., 39(9), 2811-2815, (2020)

https://doi.org/10.1007/s10067-020-05310-1

83- Bonometti R, at al., (2020)

The first case of systemic lupus erythematosus (SLE) triggered by COVID-19 infection.

Eur. Rev. Med. Pharm. Sci., 24(18), 9695-9697, (2020)

https://www.europeanreview.org/wp/wp-content/uploads/9695-9697.pdf

84- Lantos E, at al., (2020)

COVID-19-Associated Miller Fisher Syndrome: MRI Findings.

Am. J. Neuroradiol., 41(7), 1184-1186, (2020)

doi: 10.3174/ajnr.A6609 